\title{
Interactive comment on "Diurnal variability, photochemical production and loss processes of hydrogen peroxide in the boundary layer over Europe" by Horst Fischer et al.
}

Horst Fischer et al.

horst.fischer@mpic.de

Received and published: 29 May 2019

The comment was uploaded in the form of a supplement:

https://www.atmos-chem-phys-discuss.net/acp-2018-1179/acp-2018-1179-AC2-

supplement.pdf

Interactive comment on Atmos. Chem. Phys. Discuss., https://doi.org/10.5194/acp-2018-1179, 2018. 